\title{
ARTIFICIAL INTELLIGENCE SYSTEMS FOR TEACHING AND LEARNING IN CIVIL ENGINEERING: CONCEPTUAL FRAMEWORK
}

\author{
L O Toriola-Coker ${ }^{1}, \mathrm{~N}$ AYekini ${ }^{1}, \mathrm{H} \mathrm{Alaka}^{2}$ and A O Ajimo ${ }^{1}$ \\ ${ }^{1}$ School of Engineering, Yaba College of Technology, Yaba Lagos, Nigeria \\ ${ }^{2}$ University of Hertfordshire, Hatfield, Hertfordshire, UK
}

\begin{abstract}
Artificial intelligence technology is based on design of machine or computer application that mimic human intelligent. Use of artificial intelligence in teaching and learning in civil engineering is a welcome development. This paper presents a conceptual framework of Artificial Intelligence Systems for Teaching, Learning, and administration of in Civil Engineering education. The proposed system is to be designed using the following tools: Extensible Markup Language (XML) to develop the GUI, Hypertext Pre-processor (PHP) for the web user interface (WUI), APACHE for middleware, MYSQL for database design, and UML will be used to visualize the design of the system. If the system is developed and implemented, it will go a long way to advance teaching and learning, and educational administration in civil engineering profession.
\end{abstract}

\section{KEYWORDS}

Artificial Intelligence, learning management system, Civil Engineering, MYSQL, Genetic algorithm.

\section{INTRODUCTION}

Artificial intelligence (AI) has been developed through research since 1956 and was firstly used at the meeting held in Dartmouth College United State of America [1]. This was developed as a comprehensive discipline based on the teamwork of various kinds of disciplines, such as computer science, cybernetics, information theory, psychology, linguistics, and neurophysiology and civil engineering. It can also be refereed as a branch of computer science involving research, design and application of intelligent computer [1], [2]. Technological development products and establishment of relevant theories where people can progress is the aim of (AI) while its objective is to explore how to imitate and execute some of the intelligent function of human brain and other relevant technologies [3] Artificial intelligence is playing a critical role in civil engineering allowing for substantial increases in automation, directing digitalization and intelligence, reliability and performance by establishing an active connection between physical and digital construction [4], [5]. AI rise and fall in the 1950s before making great progress with the development of the fifth-generation computer in the 1980s. AI research by a single intelligent agent began to turn to the study of distributed artificial intelligence based on network environment in the 1990s where new upsurge of the research of artificial intelligence: with the development of network technology especially at the establishment of international internet technology [1], [6] Civil engineering industry as a large economic sector can influence national progress and growth as well as term development growth [7]. A projected amount of $15 \%$ of global gross domestic product (GDP) was on the rise in 2020 compared to $13 \%$ of global GDP in 2017 which was gotten from the global construction industry surveyed by McKinsey Global David C. Wyld et al. (Eds): AIAP, IT, MoWiN, CCSEIT, CNSA, ICBB - 2022 
Institute survey during their conducted exercise in 2017 [8]. Considering construction sector as one of the major contributor to the world economy representing 13\% of the global GDP with a promising $85 \%$ to $\$ 15.5$ billion globally by the year 2030 with three leading countries - China, the United States and India - contributing 57\% of its global demand [9]. Moreover world's technology leaders and governments around the world should continue to put in more effort into the implementation of AI in order to gain a competitive advantage [10]. The United Kingdom for example, recently signed an agreement by investing an additional $€ 1.8$ billion to make the country more creative and innovative putting the country at the forefront of the AI industry [11], [12]. Likewise, France proposes to spend $€ 1.5$ billion on AI science.

AI became more practical because society study not only the same goal-based distributed problem solving, but also the multiply intelligent agent's problem solving. Additionally, a thriving scene of artificial neural network research and application emerged and it had been deep into all areas of life including civil engineering learning program [1]. The experience and knowledge are unscientifically incomplete and inaccurate, and they cannot be handled by traditional procedures. However, artificial intelligence has its own superiority. It can solve complex problems to the levels of authorities by imitating the professionals. All in all, artificial intelligence has a broad application prospect in the practice of civil engineering learning.

The main theories and methods of artificial intelligence can be described as a distributed, statistical, symbolic, behaviorism and connectionism technique that focuses on simulating human functions before moving on to understanding impressionist acceptability in communication focusing on intellectual responsibilities before moving into the field of earlier approaches such as modelling and analytical representation [13]-[15]. In 1950s, AI had lots of anticipations and visions about it have been generated. Let us now elaborate the modern progress of artificial intelligence technology in all aspects of civil engineering learning and their relationship.

First, such technology provides advanced methods of learning with a competitive advantage at the tertiary level; however, they can have a positive effect on the globalization of education and researches [16], [17]. Application of this technology nowadays in many fields is fast approaching such as such as expert system, knowledge base system, intelligent database system, and intelligent robot system [1]. The decision-making and the knowledge management of the $21^{\text {st }}$ century is the expert system, which is widely acceptable as the earliest, most extensive, most active and most fruitful area in learning process. In the field of civil engineering, many problems, especially in engineering design, program decision-making and construction management were influenced by many reservations which could be solved not only in need of physics, mechanics, and mathematics calculations but also depend on the experience of experts.

Progress report were presented in the field of adaptive civil-engineering structures by Adam and Smith in 2008 describing how Self-diagnosis, multi-objective shape control, and reinforcementlearning processes were implemented within a control framework on an active tensegrity structure [18]. The suitability for modelling complex systems with known input-output data sets were among the usefulness of artificial intelligence-based computational techniques and adaptive neuro-fuzzy inference systems. Such systems can be efficient in modelling nonlinear, complex, and ambiguous behavior of cement-based materials undergoing single, dual, or multiple damage factors of different forms in civil engineering.

Recently, the development of the genetic algorithm presented many new mathematical tools and engrossed civil engineering learning as the latest achievement of applications. Due to a lot of undefined and complicated influence factors in civil engineering, each project has its individual character and generality; function of expert system in the special links and cases is a notable effect [1], [19]. We can expect, along with the computer technology, the genetic algorithm in 
civil engineering application will be more general and more effective. Over the past 20 years, in the civil engineering courses and profession, progress and application of the expert system have made a lot of accomplishments, mainly used in decision-making and prediction, building design and optimization, project evaluation, diagnosis, the construction technology and project management of roads, rails, bridges including health detection and some special field, and so on.

In recent time's artificial intelligence have been widely used in many relevant civil engineering courses such as geo-technical engineering, structural engineering, water resource engineering and so on. In the field of civil engineering, many problems, especially in engineering design, construction management and decision-making program were influenced by many doubts which could be solved not only in need of mathematics, physics and mechanic calculations but also depend on the experience of professionals. Civil engineering students need to learn how to deliver practical sustainable solutions for the engineering projects [19]. Applied assessment and award techniques was established by Thompson [20]saying it can be usefully used as teaching tools. Construction courses based on enhancing virtual computing technologies using agent-based techniques can be deploy for an e-learning environment conditions [21].

The aim of this study is to introduce AI as an auspicious administrative and learning tools that can enhance current learning efforts in the civil engineering courses including its application in construction management, geo-technical engineering, highway engineering, structural engineering, traffic engineering, water engineering and so on. The objective will be focusing at the contributions in the direction of AI in civil engineering learning in all tertiary institution. This will provide theoretical foundation or may play an important role in the development of artificial intelligence in civil engineering courses; would represent the echelons of current research of artificial intelligence in civil engineering and facilitate sustainable research efforts.

\section{LiterATURE REVIEW}

Artificial intelligence (AI) has a subfield known as Evolutionary computation (EC) which uses iterative process (often inspired by biological mechanisms of evolution) to evolve a population of solution to a desired end [1]. The application has been in existence for quite a long time within the arena of civil engineering with an effective usage for solving complex optimization problems.

The first journal article published on neural network application in civil/structural engineering was in 1989 by Adeli since then the article reviewing neural network articles published in archival research journals [22]. The great majority of civil engineering applications of neural networks are based on the simple backpropagation algorithm. AI was applied to stimulate interest within the civil engineering research community for developing the next generation results in learning.

Hayes-RothFrederick [23] in his earliest research described Genetic algorithms (GAs) as one of the renowned evolutionary algorithms which simulate the Darwinian principle of evolution and the survival of the fittest in optimization. It needs to be improved and further studied due to its extensive application in civil engineering field. A lot of improvement needed to be done in terms of technological usage of (GA) including the hybrid genetic algorithm, the dynamic adaptive technology, using nonstandard genetic operators, and the parallel genetic algorithm and so on.

Various types of Machine Learning (ML) such as (GA), Neural Network (NN), Linear Regression, Logistic Regression, Nearest-Neighbor Mapping, Decision Trees, K-Means Clustering, Random Forests, and Support Vector Machines exist for ML model implementation [9]. Several factors needed to be considered when choosing ML to be used in training time, 
accuracy, and so on. AI and ML algorithms have been attempted for use in civil engineering fields by some researchers [24]

The application of (GA) in civil engineering will be more effective and efficient if multiobjective optimization model for the scheduling of linear construction projects are implemented [25]. This model permits construction planners to appraise and generate optimal/near-optimal construction scheduling plans that minimize both project time and cost. Recently, introduction of (GA) improve many new mathematical tools and absorbed civil engineering as the latest achievement of applications.

Adaptation of immune system of a living creature was stimulated by Artificial immune system (AIS) which unravel the various complexities in real-world of engineering optimization problems [26]. Blending of the genetic algorithm and the least-squares method was used to find feasible structures and the appropriate constants for those structures in this system.

The shortcomings of the traditional and artificial neural network-based methods were disabled by the new approach which was presented in the literature for the analysis of civil engineering systems. The algorithm design has many aspects for improvement since the immune system characteristics of the application exploration is still in its initial stage, and the immune system in civil engineering application, still needing further development with the realization of the algorithm, parameter selection, the theory discussion [1].

Electimize novel evolutionary optimization algorithm was developed by Khalafallah \& AbdelRaheem [27] for solving nonlinear construction optimization problems in engineering. Another population-based global optimization technique called Particle swarm optimization (PSO) which enables a number of individual solutions, called particles, to move through a hyper dimensional search space to search for the optimum. This PSO algorithm was used to calculate the final value of every joint point in civil engineering jobs There are many ill factors impact on the quality control that are environment interference, drive saturation, measurement error, rounding error and sampling delay, in the actual operating work of the concrete pump truck [28]. The group control was used to overcome disadvantage, prove mathematical model accurate and identify parameters in full. In order to improve the joint operation real-time and accuracy, using cubic polynomial interpolation method described trajectory; adaptive robust PD control for concrete pump truck boom was used, the advantage of control law are simple and easy to implement and can guarantee a good dynamic and static quality [28]. Through the simulation examples analysis, the conclusion is that the method of combination PSO and adaptive robust PD method is suitable for concrete pump truck boom control in civil engineering works Particle Swarm Optimization (PSO) application was adopted to design and optimize the parameters of the Tuned Mass Damper (TMD) for achieving the best results in the reduction of the building and bridges response under earthquake excitations [29]. The analysis results shows that the designed PSO based TMD controller had an outstanding performance in reduction of the seismically excited example building.

A method that combines the metaheuristics Particle Swarm Optimization (PSO) with the Rough Set Theory (RST) was proposed by Filiberto et al., (2010) in order to carry out the prediction of the resistant capacity of connectors (Q) in the branch of Civil Engineering. The $k$-NN method is used to calculate this value. Similarly, a mathematical model of schedule control based on the quantitative description of the relationship between impact factors with the schedule control of the project was analyzed by [31] developing the various impact factors of project progress. Authors used the particle swarm algorithm to solve the model in order to improve the speed and accuracy of solving civil engineering learning outcomes. The empirical research showed that the method is effective in the field of project schedule control in civil engineering works. 
A novel approach based on multi-robot cooperation for inspection and repair of dome structures in civil engineering was introduced by [32]. The results of the simulations show there exists a stable path to fully sweep the surface of a dome. Small scale prototype that was experimented validated the results of findings. Finite difference method (FD) was used for the development of dynamic model of flexible beam structure in civil engineering [33]. The simulated model was validated by comparing the resonance modes with the theoretical values.

The vibration control of the beam was established through nature inspired intelligence method, the Particle Swarm Optimization (PSO), showing comparison of results with (GA) approach. The numerical simulation demonstrates that sufficient vibration suppression can be realized by means of these methods. An improved ant colony optimization (1ACO) was proposed by Kaveh \& Talatahari [34] for constrained civil engineering design problems, and applied to optimal design of different engineering problems.

Pareto Ant Colony Optimization was introduced as an especially effective meta-heuristic for solving the portfolio selection problem and compares its performance to other heuristic approaches by means of computational experiments with random instances. An efficient approach to estimate the friction coefficient via an artificial neural network was introduced as a promising computational tool in civil engineering [35]. The estimated value of the friction coefficient was used in one of the civil engineering courses in order to carry out a comparison between the proposed neural networks-based approach and the conventional ones in Manning Equation to predict the open channel flows (water engineering and fluid mechanics).

Another adaptive neural network composed of Gaussian radial functions for mapping the behavior of civil structures controlled with magnetorheological dampers was proposed for effective usage in civil engineering learning [36]. Using three types of earthquakes the proposed controller is simulated.

An AI was used as a technique of back-propagation neural networks to assess the slope failure [37]. The effectiveness of artificial neural networks in the evaluation of slope potential failure demonstrated the numerical results in civil engineering (water engineering) on five major factors, such as the slope gradient angle, the slope height, the cumulative precipitation, daily rainfall, and strength of materials.

The model of cost estimation of highway engineering was set up based on the back- progression (BP) neural network [38]. To come true quick cost-estimating the BP neural network model is trained by a sample data obtained from some performed typical engineering. According to lots of examples, it is sure that the method is practical and the estimating results are reliable. Expression has shown that BP Neural Network in cost estimate of construction engineering has a promising perspective [38].

An application of Neural Network (NN) simulation in civil engineering science was presented by Alacali et al. [39]. Predicting the lateral confinement coefficient in reinforced concrete columns is a very important issue in structural engineering [40]. Therefore, prediction have been developed through several experimental formulas. The confinement coefficient has been predicted recently using soft computing tools for artificial neural networks.

Researchers have realized that solving complex problems and analysis especially in the nonlinear problem in engineering and information technology, neural network potentiality is an important tool. The neural network will be broadly used in the civil engineering field application prospect [1]. The neural network still belongs to the new cross science, itself not perfect. Improvement research of neural network structure and algorithm still in progress where its application studies still have some problems especially in the combination method of the neural network, fuzzy logic 
genetic algorithm, and expert system. This will be a striking tool in continuous research field of civil engineering learning with the help of artificial intelligence networking

\section{Methodology AND DESIGN}

Our methodology and design will be built on the flaws from analysis of the existing system used during COVID-19 pandemic and subsequent lockdown.

\subsection{Analysis of the Existing System}

As at the time of venturing into this research work, there was no customize e-learning system for teaching and learning TVET. Majority of the institution that engaged their students virtually used social media platform like Facebook, WhatsApp, Zoom, Telegram etc. We conducted an interview for assessment of the adopted/improvised e-learning system during COVID-19 among the students and teachers in Yaba College of Technology and Lagos State Polytechnics Ikorodu. Out of two-hundred and fifteen (15) circulated to each category of the sampled population, only 199 were returned among the students while 201 were returned among the lecturers. Data collected were tabulated as in Table 1 and 2.

Table 1. Responses from Students.

\begin{tabular}{|c|c|c|c|c|c|c|c|}
\hline \multirow[b]{2}{*}{ QUESTIONS } & & \multirow[b]{2}{*}{$\begin{array}{l}\text { YE } \\
\mathbf{S}\end{array}$} & \multicolumn{5}{|c|}{ RESPONSE } \\
\hline & & & $\%$ & NO & $\%$ & $\begin{array}{l}\text { UNDECIDE } \\
\text { D }\end{array}$ & $\%$ \\
\hline $\begin{array}{l}\text { Did your school engaged Students virtually during } \\
\text { covid-19 lockdown? }\end{array}$ & A & 189 & 95.0 & 3 & 1.5 & 7 & 3.5 \\
\hline Did your school has its own eLearning platform & $\mathrm{B}$ & 0 & 0.0 & 188 & 94.5 & 11 & 5.5 \\
\hline $\begin{array}{l}\text { If YES to question } 1 \text {, did the platform used facilitate } \\
\text { the availability of course materials? }\end{array}$ & $\mathrm{C}$ & 179 & 89.9 & 13 & 6.5 & 7 & 3.5 \\
\hline $\begin{array}{l}\text { If YES to question } 1 \text {, did the platform used promote } \\
\text { autonomous learning? }\end{array}$ & $\mathrm{D}$ & 191 & 96.0 & 6 & 3.0 & 2 & 1.0 \\
\hline $\begin{array}{l}\text { If YES to question 1, did the platform enhance the } \\
\text { mastering of the course? }\end{array}$ & $\mathrm{E}$ & 39 & 19.6 & 149 & 74.9 & 11 & 5.5 \\
\hline $\begin{array}{l}\text { eLearning platform fosters didactic interaction } \\
\text { between the students and lecturers. }\end{array}$ & $\mathrm{F}$ & 176 & 88.4 & 12 & 6.0 & 11 & 5.5 \\
\hline $\begin{array}{l}\text { There is need to design a robust eLearning platform } \\
\text { that will take into consideration the needs of the } \\
\text { Polytechnic educational sector. }\end{array}$ & $\mathrm{G}$ & 199 & $\begin{array}{l}100 . \\
0\end{array}$ & 0 & 0.0 & 0 & 0.0 \\
\hline $\begin{array}{l}\text { The overall rating/assessment of eLearning platform } \\
\text { adopted by your institutions is satisfactory with } \\
\text { curriculum requirement of your course/s. }\end{array}$ & $\mathrm{H}$ & 12 & 6.0 & 181 & 91.0 & 6 & 3.0 \\
\hline
\end{tabular}




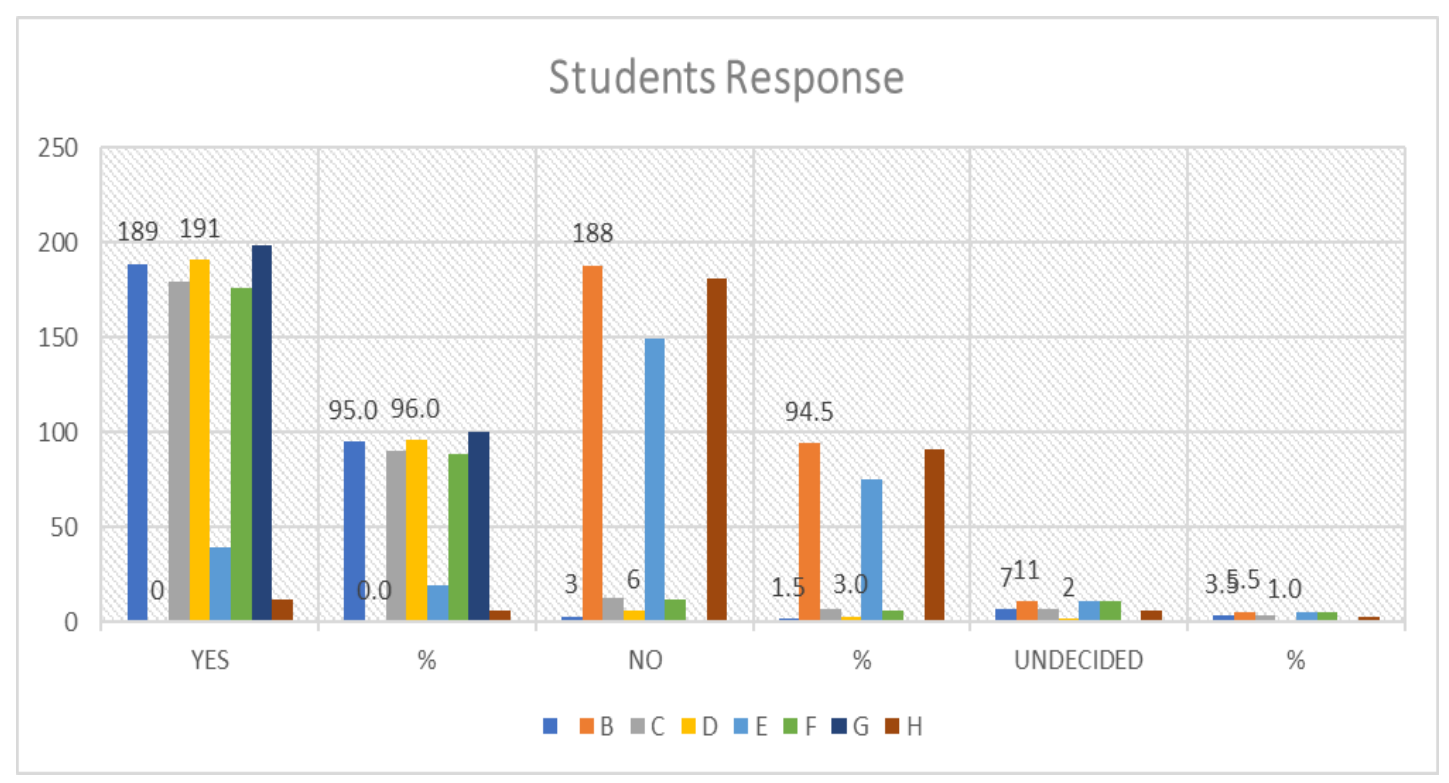

Figure 1. Student response

Table 2. Responses from the Lecturers

\begin{tabular}{|l|l|l|l|l|l|l|l|}
\hline \multicolumn{2}{|l|}{ QUESTIONS } & & \multicolumn{3}{|l|}{ RESPONSE } \\
\cline { 2 - 8 } & & YES & $\%$ & NO & \% & UNDECIDED & $\%$ \\
\hline $\begin{array}{l}\text { Did your school engaged Students } \\
\text { virtually during covid-19 lockdown? }\end{array}$ & $\mathrm{A}$ & 201 & 100.0 & 0 & 0 & 0 & 0.0 \\
\hline $\begin{array}{l}\text { Did your school has its own } \\
\text { eLearning platform }\end{array}$ & $\mathrm{B}$ & 0 & 0.0 & 201 & 100 & 0 & 0.0 \\
\hline $\begin{array}{l}\text { If YES to question 1, did the } \\
\text { platform used facilitate the } \\
\text { availability of course materials? }\end{array}$ & $\mathrm{C}$ & 63 & 31.3 & 37 & 18 & 101 & 50. \\
\hline $\begin{array}{l}\text { If YES to question 1, did the } \\
\text { platform used promote autonomous } \\
\text { learning? }\end{array}$ & $\mathrm{D}$ & 89 & 44.3 & 112 & 56 & 0 & 0.0 \\
\hline $\begin{array}{l}\text { If YES to question 1, did the } \\
\text { platform enhance the mastering of } \\
\text { the course? }\end{array}$ & $\mathrm{E}$ & 21 & 10.4 & 171 & 85 & 9 & 4.5 \\
\hline $\begin{array}{l}\text { eLearning platform fosters didactic } \\
\text { interaction between the students and } \\
\text { lecturers. F }\end{array}$ & 181 & 90.0 & 20 & 10 & 0 & 0.0 \\
\hline $\begin{array}{l}\text { There is need to design a robust } \\
\text { eLearning platform that will take } \\
\text { into consideration the needs of the } \\
\text { Polytechnic educational sector. }\end{array}$ & $\mathrm{G}$ & 201 & 100.0 & 0 & 0 & 0 & 0.5 \\
\hline $\begin{array}{l}\text { The overall rating/assessment of } \\
\text { eLearning platform adopted by your } \\
\text { institutions is satisfactory with } \\
\text { curriculum requirement of your } \\
\text { course/s. }\end{array}$ & $\mathrm{H}$ & 13 & 6.5 & 187 & 93 & 1 & \\
\hline
\end{tabular}




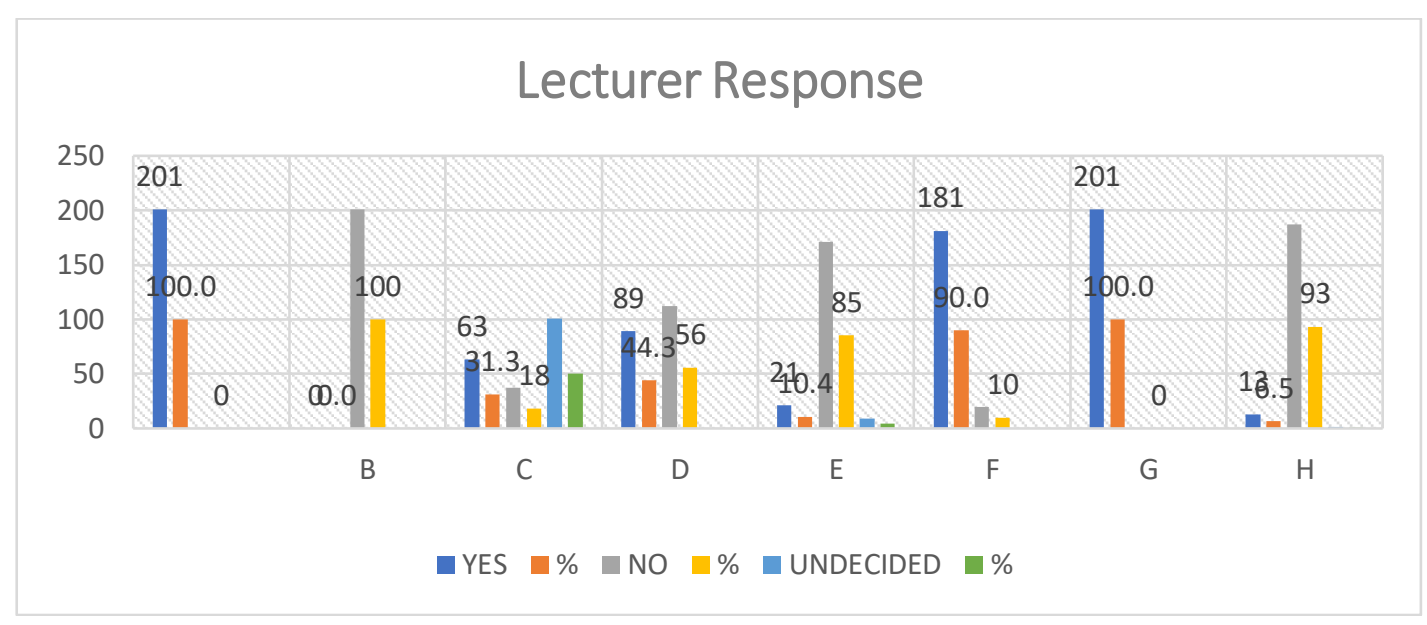

Figure 2. Lecturer response

Our findings from the analysis of data collected showed that majority of sampled population were not comfortable with e-learning platform adopted during COVID-19 pandemic in polytechnics sector. $100 \%$ of the sampled population were of opinion that there is need e-learning platform.

As mentioned in the well written and formatted introduction and review literature sections of this research work, artificial intelligence main objective is to encapsulate human intelligent in machine and it is applicable in all area of human endeavor where intelligent is needed to do one thing or the others, civil engineering profession inclusive.

In this section we present conceptual framework of cloud-based artificial intelligence learning management systems for the purpose of automation of civil engineering curriculum in Nigeria polytechnics sector.

\subsection{Design Tool}

The proposed system will have three categories of users, Administrator, Students, and Instructors (Lecturers and Technologists), and it will provide access to the students and other users through a secure Graphical User Interface (GUI). The proposed tools for the design are Extensible Markup Language (XML), Hypertext Preprocessor (PHP), APACHE, Unified Modelling Language (UML), and MYSQL. Area of the application of each tool in the design of the proposed tools are: Extensible Markup Language (XML) will be used to develop the GUI, Hypertext Preprocessor (PHP) to be used for the web user interface (WUI), APACHE will be used for middleware, and MYSQL to be used for database design, UML will be used to visualize the design of the system.

\subsection{Data Collection}

The main data required for the purposed of this research is the curriculum for teaching and learning of Civil Engineering, which will be obtain from NBTE.

\subsection{Users and their roles}

The roles of each user are as stated below. The basic activities of the proposed system will be centered on Course Registration, Audio Visual Learning Platform, and Tutorial (Attendance and grading). 
- Administrator shall perform the following roles: manage other users (Students and Instructor), backup database, maintain database etc.

- Instructors (Lecturers and technologists): manage student's account, setup virtual classes, upload curriculum, deploy learning materials, upload student's attendance, anchor virtual classes, attend to student's complaint/question, and grading of the students.

- Learners (Students): view timetable, download courseware, download result, join virtual class, make complaint, attend examination/test, view account status, and playback the previous lecture.

Access to the system will be through internet enabled mobile phones, desktop computer systems, Laptops and other handheld devices, for security of the system and data, all users will have to login before accessing the system. Figure 1, 2, 3, and 4 represents the flowchart of user's activities, and architecture of the proposed system.

\section{Working Of THE Proposed System}

The GUI will welcome the users to the proposed system, the users ought to have been enrolled and approved by the administrator before getting access to the system. Each user can then proceed to use the system after authentication. If authentication fail the users will not be allow to proceed in using the system.

It worth mentioning that the system will used supervised machine learning to perform some of it functions, consequently may have to submit query that needs to be match with the knowledge base term in the database and the provide solution or responses. 


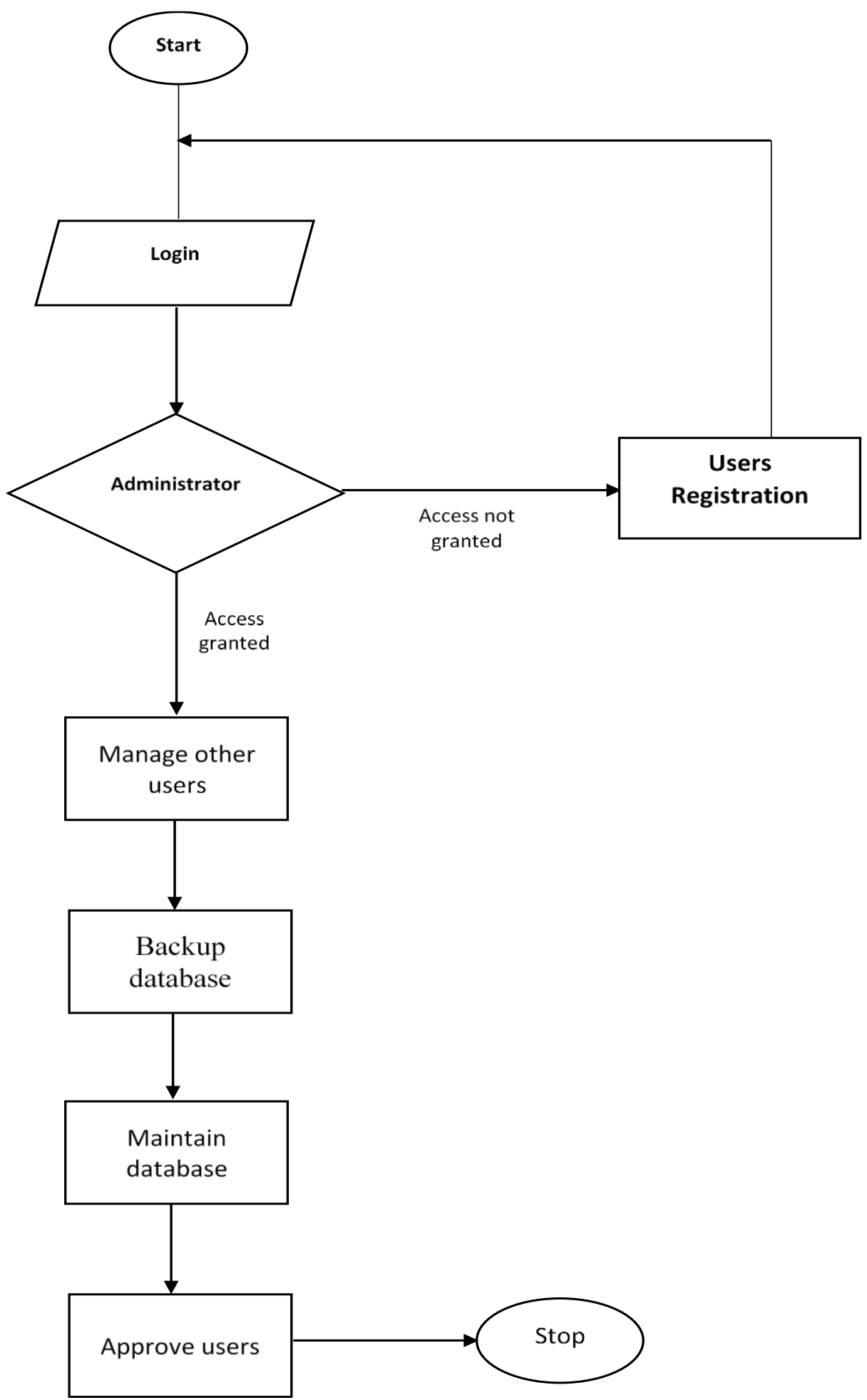

Figure 3. Administrator roles for the proposed system 


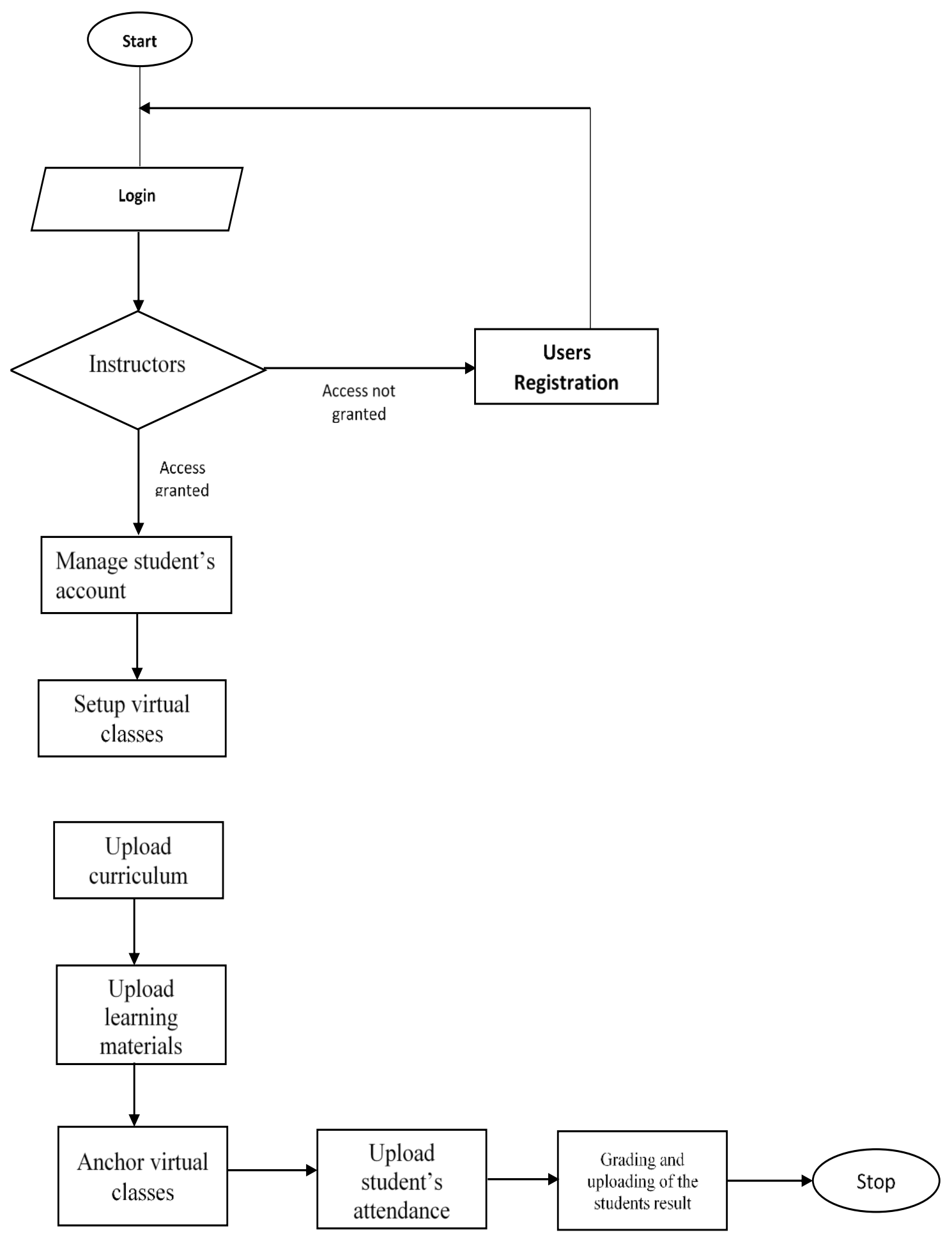

Figure 4. Instructors' roles for the proposed system 

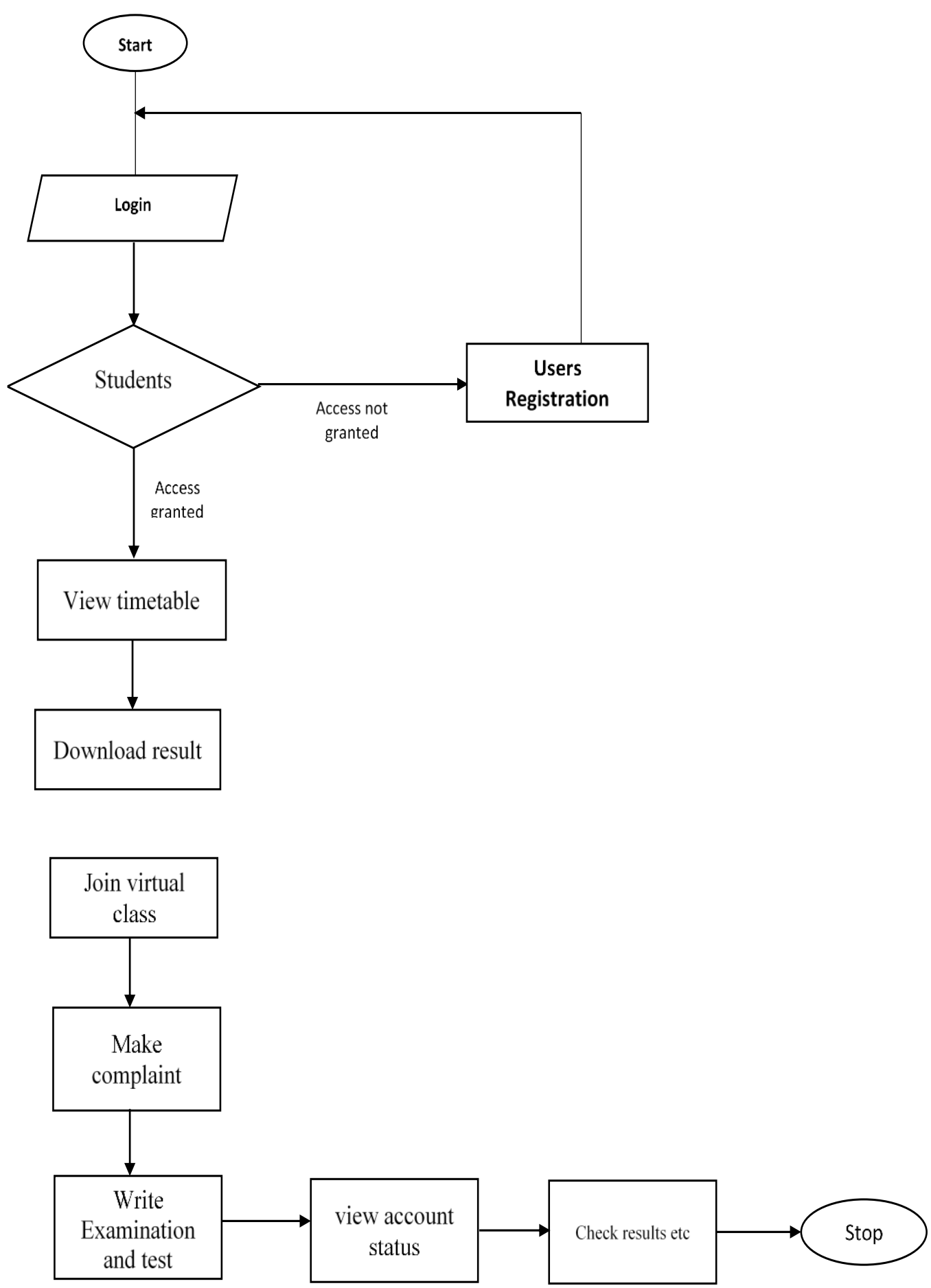

Figure 4. Student's roles of the proposed system 


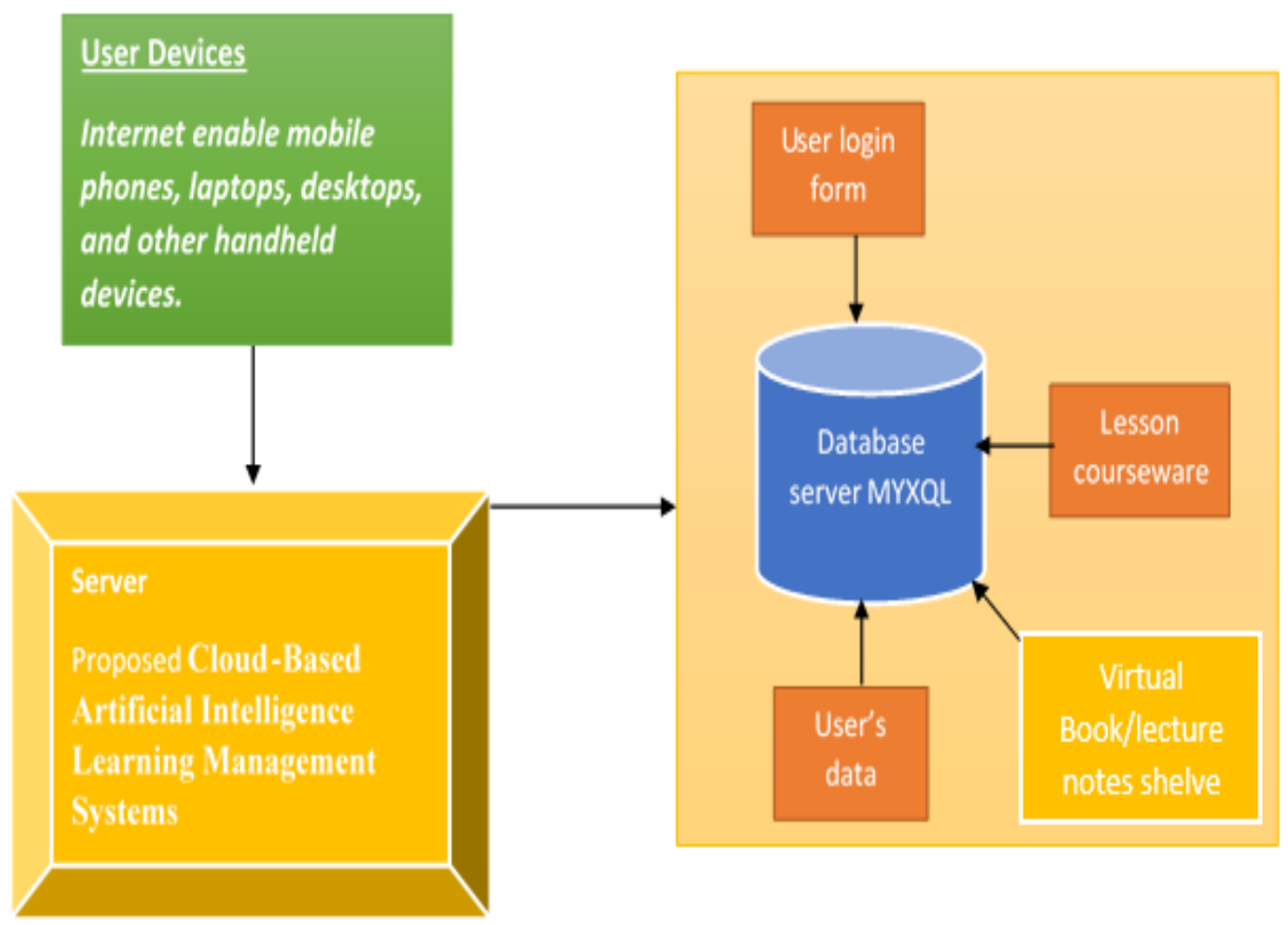

Figure 5. Architecture of the proposed System

\section{CONClusions}

This paper recapitulates and presents the relevance of artificial intelligence as an administrative and learning tool in civil engineering education. This research work presents a conceptual framework for effective online learning environment using knowledge based and supervised machine learning approach. The implementation and adoption of the proposed system will allow users access lessons, presenting lectures, grading student's exam/tests. It will also prevent niches where training is carried out completely through physical face-to-face method. Hence improve teaching and learning, and educational administration in civil engineering profession. It can be concluded from the study that artificial intelligence has a great potential to revolutionize the delivery experience of civil engineering programs at higher institutions. Future studies should look to implement the provided framework.

\section{ACKNOWLEDGEMENTS}

The authors would like to thank everyone, just everyone!

\section{REFERENCES}

[1] P. Lu, S. Chen, and Y. Zheng, "Artificial intelligence in civil engineering," Math. Probl. Eng., vol. 2012, 2012, doi: 10.1155/2012/145974.

[2] A. U. Hosna, A. K. M. F. Ahmad, and J. U. Sun, "A Two-Step Local Search Enhancement with the Novel Solution Representation for Solving Capacitated Vehicle Routing Problems," Adv. Sci. Lett., vol. 25, no. 1, pp. 95-99, Jan. 2019, doi: 10.1166/ASL.2019.13195.

[3] S. Chen, Y. Zheng, C. Cattani, and W. Wang, "Modeling of biological intelligence for SCM system optimization," Comput. Math. Methods Med., vol. 2012, 2012, doi: 10.1155/2012/769702. 
[4] D. Luckey, H. Fritz, D. Legatiuk, K. Dragos, and K. Smarsly, "Artificial Intelligence Techniques for Smart City Applications," in Computing in Civil and Building Engineering, 2021, vol. 98, pp. 3-15, doi: 10.1007/978-3-030-51295-8_1.

[5] A. Tavana Amlashi, P. Alidoust, M. Pazhouhi, K. Pourrostami Niavol, S. Khabiri, and A. Reza Ghanizadeh, "AI-based formulation for mechanical and workability properties of eco-friendly concrete made by waste foundry sand," ascelibrary.org, 2020, doi: 10.1061/(ASCE)MT.19435533.0003645 .

[6] C. M. Pintea, C. P. Sitar, M. Hajdu-Macelaru, and P. Petrica, "A Hybrid Classical Approach to a Fixed-Charged Transportation Problem," in International Conference on Hybrid Artificial Intelligence Systems, 2012, vol. 7208 LNAI, no. PART 1, pp. 557-566, doi: 10.1007/978-3-64228942-2 50 .

[7] D. T. H. Giang and L. Sui Pheng, "Role of construction in economic development: Review of key concepts in the past 40 years," Habitat Int., vol. 35, no. 1, pp. 118-125, Jan. 2011, doi: 10.1016/J.HABITATINT.2010.06.003.

[8] McKinsey\&Company, "REINVENTING CONSTRUCTION: A ROUTE TO HIGHER PRODUCTIVITY," Feb. 2017.

[9] C. N. Egwim, H. Alaka, L. O. Toriola-Coker, H. Balogun, and F. Sunmola, "Applied artificial intelligence for predicting construction projects delay," Mach. Learn. with Appl., vol. 6, p. 100166, Dec. 2021, doi: 10.1016/J.MLWA.2021.100166.

[10] P. Kumar Donepudi, A. Al Ayub Ahmed, C. Author, and S. Saha--EMERGING MARKET, "Emerging Market Economy (EME) and Artificial Intelligence (AI): Consequences for the Future of Jobs," archives.palarch.nl, vol. 17, no. 6, pp. 5562-5574, 2020.

[11] S. Shirowzhan, W. Tan, and S. M. E. Sepasgozar, "Digital twin and CyberGIS for improving connectivity and measuring the impact of infrastructure construction planning in smart cities," Int. J. Geo-Information, pp. 1-11, Apr. 2020, doi: 10.3390/ijgi9040240.

[12] M. S. Stojči'c, E. Kazimieras Zavadskas, D. Pamučar, Ž. S. Stevi'c, and A. Mardani, "Application of MCDM methods in sustainability engineering: A literature review 2008-2018," mdpi.com, pp. 1-24, Mar. 2019, doi: 10.3390/sym11030350.

[13] A. K. Feroz, H. Zo, and A. Chiravuri, "Digital Transformation and Environmental Sustainability: A Review and Research Agenda," Sustain. 2021, Vol. 13, Page 1530, vol. 13, no. 3, p. 1530, Feb. 2021, doi: $10.3390 /$ SU13031530.

[14] D. Ciresan, U. Meier, and J. Schmidhuber, "Multi-column Deep Neural Networks for Image Classification Supplementary Online Material," Comput. Vis. Pattern Recognit. (CVPR), 2012 IEEE Conf., no. February, pp. 3642-3649, 2012.

[15] M. A. Goralski and T. K. Tan, "Artificial intelligence and sustainable development," Int. J. Manag. Educ., vol. 18, no. 1, p. 100330, Mar. 2020, doi: 10.1016/J.IJME.2019.100330.

[16] D. Pamučar, D. Božanić, ... V. L.-F. universitatis, and U. 2018, "Normalized weighted geometric bonferroni mean operator of interval rough numbers-application in interval rough dematel-copras model," casopisi.junis.ni.ac.rs, vol. 16, no. 2, pp. 171-191, Jun. 2018, doi: 10.22190/FUME180503018P.

[17] A. Taeihagh, "Governance of artificial intelligence," https://doi.org/10.1080/14494035.2021.1928377, vol. 40, no. 2, pp. 137-157, 2021, doi: 10.1080/14494035.2021.1928377.

[18] B. Adam, I. S.-C. \& Structures, and U. 2008, "Active tensegrity: A control framework for an adaptive civil-engineering structure," Elsevier, vol. 86, pp. 2215-2223, 2008.

[19] V. Singh, S. Bano, | Anand, K. Yadav, S. Ahmad, and A. K. Yadav, "Feasibility of Artificial Neural Network in Civil Engineering International Journal of Trend in Scientific Research and Development (IJTSRD) Feasibility of Artificial Neural Network in Civil Engineering the Creative Commons Attribution License (CC BY 4.0)," Int. J. Trend Sci. Res. Dev., vol. 3, no. 3, pp. 724-728, Apr. 2019.

[20] P. Thompson, "Teaching sustainability in civil engineering using Ceequal," in http://dx.doi.org/10.1680/ensu.2010.163.4.209, May 2015, vol. 163, no. 4, pp. 209-217, doi: 10.1680/ENSU.2010.163.4.209.

[21] E. A. Obonyo, "An agent-based intelligent virtual learning environment for construction management," Constr. Innov., vol. 11, no. 2, pp. 142-160, 2011, doi: 10.1108/14714171111124130/FULL/XML.

[22] H. Adeli, "Neural Networks in Civil Engineering: 1989-2000," Comput. Civ. Infrastruct. Eng., vol. 16, no. 2, pp. 126-142, Mar. 2001, doi: 10.1111/0885-9507.00219. 
[23] Hayes-RothFrederick, "Review of 'Adaptation in Natural and Artificial Systems by John H. Holland', The U. of Michigan Press, 1975," ACM SIGART Bull., no. 53, pp. 15-15, Aug. 1975, doi: 10.1145/1216504.1216510.

[24] C. Q. X. Poh, C. U. Ubeynarayana, and Y. M. Goh, "Safety leading indicators for construction sites: A machine learning approach," Autom. Constr., vol. 93, pp. 375-386, Sep. 2018, doi: 10.1016/J.AUTCON.2018.03.022.

[25] A. Senouci and H. R. Al-Derham, "Genetic algorithm-based multi-objective model for scheduling of linear construction projects," Adv. Eng. Softw., vol. 39, no. 12, pp. 1023-1028, Dec. 2008, doi: 10.1016/J.ADVENGSOFT.2007.08.002.

[26] J. D. Farmer, N. H. Packard, and A. S. Perelson, "THE IMMUNE SYSTEM, ADAPTATION, AND MACHINE LEARNING," pp. 187-204, 1986.

[27] A. Khalafallah and M. Abdel-Raheem, "Electimize: New Evolutionary Algorithm for Optimization with Application in Construction Engineering," J. Comput. Civ. Eng., vol. 25, no. 3, pp. 192-201, Jul. 2010, doi: 10.1061/(ASCE)CP.1943-5487.0000080.

[28] T. Wang, G. Wang, and K. Liu, "Simulation control of concrete pump truck boom based on PSO and adaptive robust PD," in 2009 Chinese Control and Decision Conference, CCDC 2009, Jun. 2009, pp. 960-963, doi: 10.1109/CCDC.2009.5192810.

[29] K. Ghaedi, Z. Ibrahim, H. Adeli, and A. Javanmardi, "Invited Review: Recent developments in vibration control of building and bridge structures," J. Vibroengineering, vol. 19, no. 5, pp. 35643580, Aug. 2017, doi: 10.21595/JVE.2017.18900.

[30] Y. Filiberto, R. Bello, Y. Caballero, and R. Larrua, "Using PSO and RST to Predict the Resistant Capacity of Connections in Composite Structures," Stud. Comput. Intell., vol. 284, pp. 359-370, 2010, doi: 10.1007/978-3-642-12538-6_30.

[31] X. Zheng and Z. Liu, "The schedule control of engineering project based on particle swarm algorithm," 2010 2nd Int. Conf. Commun. Syst. Networks Appl. ICCSNA 2010, vol. 1, pp. 184-187, 2010, doi: 10.1109/ICCSNA.2010.5588681.

[32] A. Nejadfard, H. Moradi, and M. N. Ahmadabadi, "A multi-robot system for dome inspection and maintenance: Concept and stability analysis," in International Conference on Robotics and Biomimetics, ROBIO 2011, Dec. 2011, pp. 853-858, doi: 10.1109/ROBIO.2011.6181394.

[33] V. Raju, D. Maheswari, and S. K. Patnaik, "Active vibration control of piezo actuated cantilever beam using PSO," in Students' Conference on Electrical, Electronics and Computer Science: Innovation for Humanity, SCEECS 2012, Mar. 2012, p. 289, doi: 10.1109/SCEECS.2012.6184834.

[34] A. Kaveh and S. Talatahari, "An improved ant colony optimization for constrained engineering design problems," Eng. Comput. (Swansea, Wales), vol. 27, no. 1, pp. 155-182, Jan. 2010, doi: 10.1108/02644401011008577/FULL/XML.

[35] A. Bilgil and H. Altun, "Investigation of flow resistance in smooth open channels using artificial neural networks," Flow Meas. Instrum., vol. 19, no. 6, pp. 404-408, Dec. 2008, doi: 10.1016/J.FLOWMEASINST.2008.07.001.

[36] J. Simon Laflamme, J. J. Connor, and S. Laflamme, "Application of self-tuning Gaussian networks for control of civil structures equipped with magnetorheological dampers," https://doi.org/10.1117/12.815540, vol. 7288, no. 6, pp. 271-282, Apr. 2009, doi: 10.1117/12.815540.

[37] T. L. Lee, H. M. Lin, and Y. P. Lu, "Assessment of highway slope failure using neural networks," J. Zhejiang Univ. A 2009 101, vol. 10, no. 1, pp. 101-108, Jan. 2009, doi: 10.1631/JZUS.A0820265.

[38] C. Wang et al., "Application of neural network in the cost estimation of highway engineering," $J$. Comput., vol. 5, no. 11, pp. 1762-1766, Nov. 2010, doi: 10.4304/jcp.5.11.1621-1628.

[39] S. N. Alacali, B. Akba, and B. Doran, "Prediction of lateral confinement coefficient in reinforced concrete columns using neural network simulation," Appl. Soft Comput., vol. 11, no. 2, pp. 26452655, Mar. 2011, doi: 10.1016/J.ASOC.2010.10.013.

[40] M. Naeej, M. Bali, M. R. Naeej, and J. V. Amiri, "Prediction of lateral confinement coefficient in reinforced concrete columns using M5' machine learning method," KSCE J. Civ. Eng. 2013 177, vol. 17, no. 7, pp. 1714-1719, Oct. 2013, doi: 10.1007/S12205-013-0214-3. 
AUTHOR

Dr Engr. TORIOLA-COKER holds higher national diploma HND (Civil Engineering), Master in Engineering MEng (Civil Engineering), Doctor of Philosophy $\mathrm{PhD}$ (Construction and Project Management) and professional certificates of Registered Engineer of Council for the Regulation of Engineering in Nigeria (COREN), Member of Nigeria Society of Engineer (NSE), Member of Environment Division of Nigeria Society of Engineer (NSE), Member of

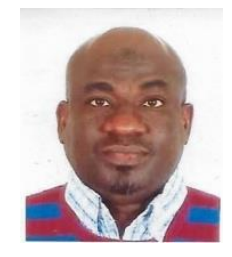
Construction Skills Certification Scheme (CSCS) UK, Track Certificate Holder on Rail Network UK and Sentinel Card Holder on Rail Network UK. He lectures at Yaba College of Technology and served as Class Adviser and Coordinator in the department of Civil Engineering. Dr Engr. TORIOLA-COKER is actively involved in academic and professional aspects of Transportation, Highway, Railway and Construction Engineering. Apart from these academic and professional engagements he has been involved in current projects in waste management under the auspices of Innovative UK. Dr Engr. TORIOLA-COKER has supervised student projects at undergraduate and graduate level in the core aspect of Civil Engineering among others and has contributed to articles in academic journals and conferences at local and international levels. He has also published \& contributed to academic books.

(C) 2022 By AIRCC Publishing Corporation. This article is published under the Creative Commons Attribution (CC BY) license. 